\title{
Meta-analysis of early versus late closure of a temporary ileostomy after proctectomy
}

\author{
Xiaozhun Huang ${ }^{1, *}$, Chunling Wang ${ }^{2, *}$, Zhangkan Huang ${ }^{1}$, Houhong Zhou ${ }^{1}$, Han Li $^{1}$, \\ Fengxiang $\mathrm{Shi}^{3}$, Longde $\mathrm{Du}^{4}$, Xianni $\mathrm{Ke}^{5}$, Biao Zheng ${ }^{1}$, Shuisheng Zhang ${ }^{6}$ and $\mathrm{Xu}$ \\ Che $^{6}$ \\ ${ }^{1}$ Department of Abdominal Surgery, National Cancer Center/Cancer Hospital \& Shenzhen Hospital, Chinese Academy of \\ Medical Sciences and Peking Union Medical College, Shenzhen 518116, China \\ ${ }^{2}$ Department of Hepatology, Huizhou Municipal Central Hospital, Huizhou 516000, China \\ ${ }^{3}$ Department of Medical Statistics and Epidemiology, School of Public Health, Sun Yat-Sen University, Guangzhou 510080, \\ China \\ ${ }^{4}$ Department of Thoracic Surgery, National Cancer Center/Cancer Hospital \& Shenzhen Hospital, Chinese Academy of Medical \\ Sciences and Peking Union Medical College, Shenzhen 518116, China \\ ${ }^{5}$ Department of Medical Oncology, National Cancer Center/Cancer Hospital \& Shenzhen Hospital, Chinese Academy of Medical \\ Sciences and Peking Union Medical College, Shenzhen 518116, China \\ ${ }^{6}$ Department of Pancreatic and Gastric Surgery, National Cancer Center/Cancer Hospital, Chinese Academy of Medical \\ Sciences and Peking Union Medical College, Beijing 100021, China \\ *These authors have contributed equally to this work \\ Correspondence to: Xu Che, email: drchexu@126.com \\ Shuisheng Zhang, email: thelifeofwater@126.com
}

Keywords: temporary ileostomy; early closure; late closure; complication; hospital stay

Received: November 08, $2017 \quad$ Accepted: January 03, $2018 \quad$ Published: January 02, 2018

Copyright: Huang et al. This is an open-access article distributed under the terms of the Creative Commons Attribution License 3.0 (CC BY 3.0), which permits unrestricted use, distribution, and reproduction in any medium, provided the original author and source are credited.

\section{ABSTRACT}

Background: A temporary ileostomy is frequently constructed to reduce the risk of symptomatic anastomotic leakage. An ostomy is a heavy burden on both patient and society, and early closure is therefore desirable to counteract increased morbidity. The optimal time for stoma closure has been investigated in some studies, although it remains controversial.

Methods: We conducted a literature search of PubMed, Wiley, Web of Science, and the Cochrane Library to identify studies published till 2017 that focused on perioperative complications and details related to early ( $<4$ weeks) and late( $>4$ weeks) closure of temporary ileostomies after proctectomy.

Results: Six studies (three randomized controlled trials, two prospective nonrandomized trials, and one retrospective trial) satisfied our inclusion criteria, and the outcomes of 767 patients ( 356 early closures and 411 late closures) were analyzed. There was a significantly lower prevalence of skin irritation $(p=0.0002)$ in the early group, but no worse morbidity outcomes were observed between the early and late closure groups. Hospital stay length after an ileostomy closure was not prolonged following early closure, suggesting that the increased wound infection risk did not significantly delay discharge. Also, the overall hospital stay length, when time since admission for the original operation was included in the late closure group, showed no significantly longer duration in the early closure group $(p=0.02)$.

Conclusions: We found that early closure of a temporary ileostomy after proctectomy was feasible in selected patients, with some advantages and disadvantages that need to be weighed by the patient and surgeon. 


\section{INTRODUCTION}

Patients undergoing a low rectal resection may receive a temporary ileostomy to reduce the risk of symptomatic anastomotic leakage [1]. Anastomotic leakage is the most feared complication of colorectal surgery, and to decrease the risk of occurrence, some surgeons suggest that a temporary stoma should be formed to reduce intraluminal pressure on the bowel by a proximal fecal diversion, so that the distal anastomosis is kept relatively "clean" [2]. A defunctioning loop ileostomy is effective for reducing both the rate of symptomatic anastomotic leakage and the need for a reoperation, as proved by randomized controlled trials (RCTs) [1] and meta-analyses [3, 4]. Thus, the procedure is recommended for selected patients with high-risk anastomoses [3]. A temporary loop ileostomy is preferred to a colostomy by most surgeons because it is easy to construct and close without risk of injury to the colic vascular arcade, and there are fewer problems with prolapses [5]. However, the construction of a temporary stoma is associated with higher costs for patients and society alike. Stoma-related morbidity of a temporary ileostomy includes dehydration from high stoma output and the risk of a postoperative bowel obstruction [6]. Therefore, patients experience reduced quality-of-life due to physical and mental restrictions as well as some debilitating effects that are a nuisance [7].

Some meta-analyses have reported that a temporary ileostomy does not prevent an anastomotic leakage [3, 8]. Many patients will keep their ileostomy for at least 3 months, often longer, and for some patients, it becomes permanent [9]. Furthermore, patients with rectal cancer are increasingly being offered a postoperative adjuvant treatment, which creates some uncertainty about the timing of stoma closure [10]. Early closure of atemporary loop ileostomy may reduce both stoma-related complications and patient discomfort.

A systematic review showed that closure of a temporary ileostomy was associated with low mortality $(0.4 \%)$, but overall morbidity following a loop ileostomy closure ranged from $17.3 \%$ [11] to $28 \%$ [12]. The concept of a mature and adequately safe closure of such a stoma has been debated for some time now. The timing of stoma closure has been investigated in some studies to define the feasibility of early versus delayed reversal of a defunctioning ileostomy [13-15], yet, it remains controversial. No meta-analysis data that determine the safety and optimal time for the closure of a temporary diversion of the small bowel, suggesting that there is no need to discard the current concept that a stoma is mature by $8-12$ weeks, although some authors have provided evidence of safe closure as early as 6 days postoperatively [16].

We conducted a meta-analysis of all RCTs and observational studies that compared complications and hospital stay length after early or late closure of a temporary ileostomy. These results will assist surgeons when making decisions regarding the optimal time to close a temporary stoma.

\section{RESULTS}

\section{Search results}

Details of the initial search results and refined inclusions are presented in Figure 1; a total of 873 references were identified from medical journal databases. After the removal of 166 duplicates and 699 exclusions, because their titles or abstracts described topics that were unsuitable for this study, 23 full-text articles were reviewed. Of these, four were reviews [17, $18]$ or only abstracts $[15,19]$, one was a duplicate report [20], one was a trial without related data pertaining to the outcome of an early orlate ileostomy closure [21], and a comparative protocol was unfeasible in 10 studies [22-31]. The remaining six studies $[13,14,16$, $32-34]$ that compared early with late closure ileostomy were included in the meta-analysis. An examination of references listed for these six studies and for review articles did not yield any further studies for evaluation. Agreement between the two reviewers was $83.3 \%$ for study selection and $83.3 \%$ for quality assessment of trials.

\section{Characteristics of the included studies}

The characteristics of the six studies included in the meta-analysis are summarized in Table 1 . They were published between 2005 and 2017 and include three RCTs $[13,14,16]$, two prospective studies [32, 34], and one retrospective study [33]. The sample size ranged from 26 to 311 , with a total of 767 participants: 356 in the early closure group (46.4\%) and 411 in the late closure group (53.6\%).

\section{Methodological quality of the included studies}

The quality of all included studies was generally high (Supplementary Tables 1 and 2) and true randomization was used in all, including RCTs. One retrospective and one prospective study did not adopt an appropriate protocol for treatment assignment, and all ocation was usually at the discretion of the surgeon. All RCTs provided information on allocation concealment, and blinding of the intervention was not possible. Three studies mentioned the follow-up duration, and half of the studies provided only perioperative data. Methods for handling missing data and the intention-to-treat analysis were adequately described in the majority of RCTs. 


\section{Primary outcomes}

\section{Perioperative complications}

When data from the six studies were pooled, perioperative complications in 767 patients showed no significant difference between the early and late closure groups $[9.4 \%$ and $7.6 \%$, respectively; odds ratio $(\mathrm{OR})$ : $1.32 ; 95 \%$ confidence intervals (CI): $0.97-1.80 ; p=0.08]$ (Figure 2). There was a higher prevalence of wound infection in the early closure group $(16 \% ; 57 / 356)$ than in the late closure group $(6.57 \%$; $27 / 411$ patients) (OR: 2.76; 95\%CI: $1.70-4.50 ; p=0.49$; Figure 2$)$. The early closure group also had a lower prevalence of obstruction $(3.78 \% ; 7 / 185)$ compared with that in the late closure group $(10.3 \%$; 24/232) (OR: 0.36 ; 95\%CI: $0.15-0.86 ; p=$ 0.27 ; Figure 2). Anastomotic leakage and reoperation rates were available for three $[13,14,32]$ and two studies [13, 14], respectively, and there were no significant differences between the two groups $(6.54 \%$ and $7.59 \%$; OR: 0.84 ; $95 \%$ CI: $0.45-1.56 ; p=0.58$; and $6.67 \%$ and $5.41 \%$; OR: 1.23 ; 95\% CI: $0.27-3.23 ; p=0.63$, respectively).

Overall, 112 and 125 events related to stoma closure were observed in the early and late closure groups, respectively. A cumulative analysis of outcome measures demonstrated no significant difference between the early and late closure groups (OR: $1.20 ; 95 \%$ CI: $0.70-2.06 ; p$ $=0.51$; Figure 2 ).

\section{Secondary outcomes}

\section{Operative time}

All three trials $[13,14,33]$ reported operative time in 324 patients, and the late closure group appeared to need a slightly longer operative time. However, a meta-analysis using the random effects model found no significant difference in the operative time between the early and late closure groups [weighted mean difference (WMD) 12.63 min shorter in the early closure group, 95\%CI: $-28.76-$ $3.51 ; p=0.13$ ] (Figure 3A). Statistical heterogeneity was found $\left(\tau^{2}=162.99, \chi^{2}=30.91 ; p<0.00001, I^{2}=94 \%\right)$.

\section{Postoperative hospital stay}

All studies reported hospital stay after the closure, and a meta-analysis using the fixed effects model revealed no significant difference in the hospital stay length between the early and late closure groups (WMD 0.03

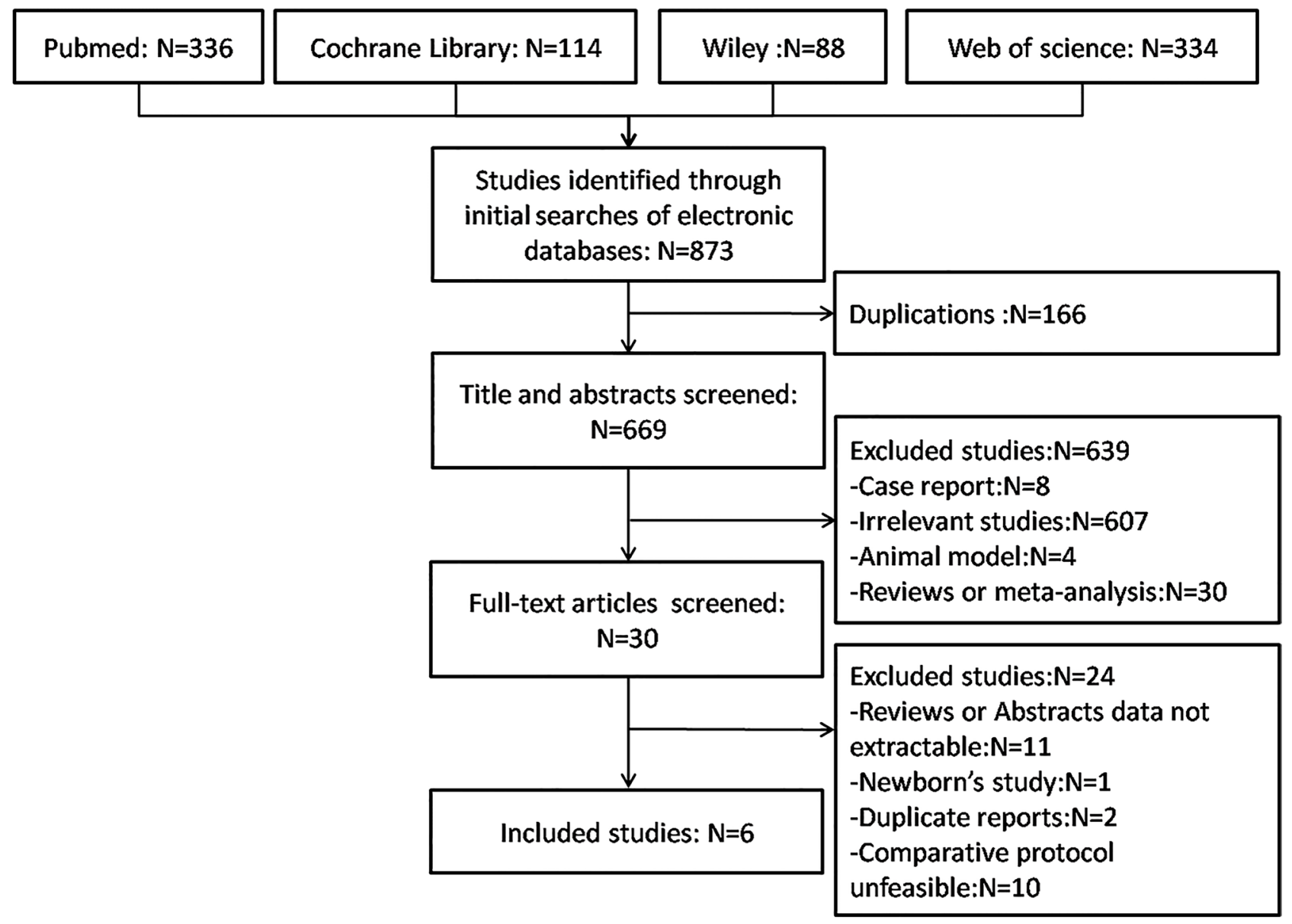

Figure 1: Flow diagram of the studies identified, included, and excluded. 
Table 1: Study characteristics and outcomes of interest reported by each of the included studies

\begin{tabular}{|c|c|c|c|c|c|c|c|c|c|}
\hline References & Design & Early & Late & $\begin{array}{c}\text { Females } \\
\mathbf{N}(\%)\end{array}$ & $\begin{array}{c}\text { Stoma } \\
\text { indication }\end{array}$ & Diseases matching & $\begin{array}{c}\text { Study } \\
\text { quality }\end{array}$ & Complications & $\begin{array}{c}\text { Operative } \\
\text { details }\end{array}$ \\
\hline Alves [14] & $\mathrm{RCT}$ & 95 & 91 & 53.8 & 1a & $2 \mathrm{a}, 2 \mathrm{~b}, 2 \mathrm{~d}, 2 \mathrm{e}, 2 \mathrm{f}$ & $\mathrm{RCT}$ & $3 \mathrm{a}, 3 \mathrm{~b}, 3 \mathrm{c}, 3 \mathrm{~d}, 3 \mathrm{e}$ & $4 a, 4 b$ \\
\hline Danielsen [13] & RCT & 55 & 57 & 46.4 & $1 \mathrm{a}$ & $2 \mathrm{a}$ & $\mathrm{RCT}$ & $3 \mathrm{a}, 3 \mathrm{~b}, 3 \mathrm{c}, 3 \mathrm{~d}, 3 \mathrm{e}$ & $4 a, 4 b, 4 c$ \\
\hline Lasithiotakis [16] & $\mathrm{RCT}$ & 16 & 10 & 42.3 & $1 \mathrm{a}$ & $2 a, 2 f$ & $\mathrm{RCT}$ & $3 a, 3 b$ & $4 a, 4 b$ \\
\hline Omundsen [33] & RET & 19 & 74 & $\mathrm{n} / \mathrm{c}$ & 1a & $\begin{array}{c}2 \mathrm{a}, 2 \mathrm{~b}, 2 \mathrm{c}, 2 \mathrm{~d}, 2 \mathrm{e} \\
2 \mathrm{f}\end{array}$ & $6 \star$ & $3 a, 3 b$ & $4 b, 4 c$ \\
\hline Khan [32] & PNR & 156 & 155 & 44.1 & $1 \mathrm{a}$ & $2 \mathrm{a}, 2 \mathrm{~d}, 2 \mathrm{f}$ & $6 \star$ & $3 \mathrm{a}, 3 \mathrm{c}, 3 \mathrm{f}, 3 \mathrm{~g}$ & $4 \mathrm{~b}$ \\
\hline Perejordi-Galais [34] & PNR & 15 & 24 & 53.8 & $1 b$ & $2 \mathrm{a}, 2 \mathrm{c}, 2 \mathrm{~d}, 2 \mathrm{f}$ & $6 \star$ & $3 a$ & $4 b, 4 c$ \\
\hline
\end{tabular}

RCT, randomized controlled trial; RET, retrospective; PNR, prospective non-randomized; n/c, no comment; Stoma: 1a, temporary loop ileostomy; $1 \mathrm{~b}$, temporary stoma of the small bowel loop ileostomy; Diseases: $2 \mathrm{a}$, rectal cancer, $2 \mathrm{~b}$, gynecological benign diseases; 2c, gynecological malignant diseases; $2 \mathrm{~d}$, inflammatory bowel disease; 2e, genetic intestinal disease; 2c, other benign diseases; Complications of stoma closure: $3 \mathrm{a}$, wound infection; $3 \mathrm{~b}$, obstruction; $3 \mathrm{c}$, anastomotic leakage; $3 \mathrm{~d}$, reoperation; $3 \mathrm{e}$, bleeding; $3 \mathrm{f}$, skin irritation; $3 \mathrm{~g}$, mortality; operative details: 4a, operative time; $4 \mathrm{~b}$, hospital duration after closure; $4 \mathrm{c}$, total length of hospital duration.

days shorter in the early closure group; $95 \% \mathrm{CI}:-0.62-$ $0.55 ; p=0.91$ ) (Figure 3B). Statistical heterogeneity was not found $\left(\tau^{2}=0.00, \chi^{2}=2.98 ; p=0.70, I^{2}=0 \%\right)$.

\section{Total hospital stay length}

Three studies reported on the total length of hospital stay, the early closure group had a reduced total hospital duration, but a meta-analysis using the random effects model found no significant difference (WMD 3.47days shorter in the early closure group; $95 \% \mathrm{CI}:-7.95-1.00 ; p$ $=0.02)$ (Figure $3 \mathrm{C})$. Statistical heterogeneity was found $\left(\tau^{2}\right.$ $=10.65, \chi^{2}=7.51 ; p=0.02, I^{2}=73 \%$ ).

\section{Sensitivity analysis and publication bias}

Three RCTs, one retrospective study, and two prospective studies that scored six or more stars on the modified Newcastle-Ottawa scale were included in the sensitivity analysis. There was no change in the significance of any complication outcomes, which was shown as not significantly lower in the early closure group than that in the late closure group (OR: 1.20; 95\%CI: $0.70-2.06 ; p=0.51)$. The degree of betweenstudy heterogeneity slightly decreased for complications and hospital duration but not for operative time.

There was no significant difference in publication bias as determined using the Begg's rank correlation test $(p=1.000$; Figure 4A) and the Egger linear regression method ( $p=0.856$; Figure 4B).

\section{DISCUSSION}

This meta-analysis of three RCTs and three observational studies compared the efficacy of early versus late closure ileostomy after proctectomy in 767 patients. We showed that early closure of stoma was safe with significant skin irritation, and we found no significant differences in anastomotic leakage, obstruction, reoperation, bleeding, or mortality. Therefore, outcome measures analyzed for the closure of an ileostomy showed a higher prevalence of wound infection in early closure versus late closure. Outcome measures analyzed for operative time revealed no advantages for early closure. The analysis of hospital stay after closure revealed advantages for early closure in terms of hospital stay length after closure, but the total length of the hospital stay length showed no difference.

Gastrointestinal continuity is usually restored after a period of 8-12 weeks following an ileostomy [35]. This delay is considered necessary to allow patients plenty of time to fully recover from their index operation, but also to reduce the incidence of bowel friability and adhesions, which enable easier ileostomy reversal $[10,36]$. Closing the stoma earlier than that time is thought to be associated with marked peristomal and intraperitoneal adhesions, making surgery more hazardous $[10,36]$. However, the best time for reversing an ileostomy remains controversial and a high percentage of patients will experience stomarelated complications during this period.

A recent systematic review by Robertson et al. [37] in 2015, considered the early closure of a defunctioning loop ileostomy to be safe, and it reduced stoma-related morbidity. However, they stated that the availability of sufficient quality supporting evidence was limited. Only one RCT [14] was included in the analysis. Compared with a traditionally timed closure, the reported stomarelated complication rate was lower in patients who underwent early closure. Both mortality and ileus/small bowel obstruction(SBO) rates also compared favorably with a traditionally timed closure; however, wound infection rates appeared to increase. 


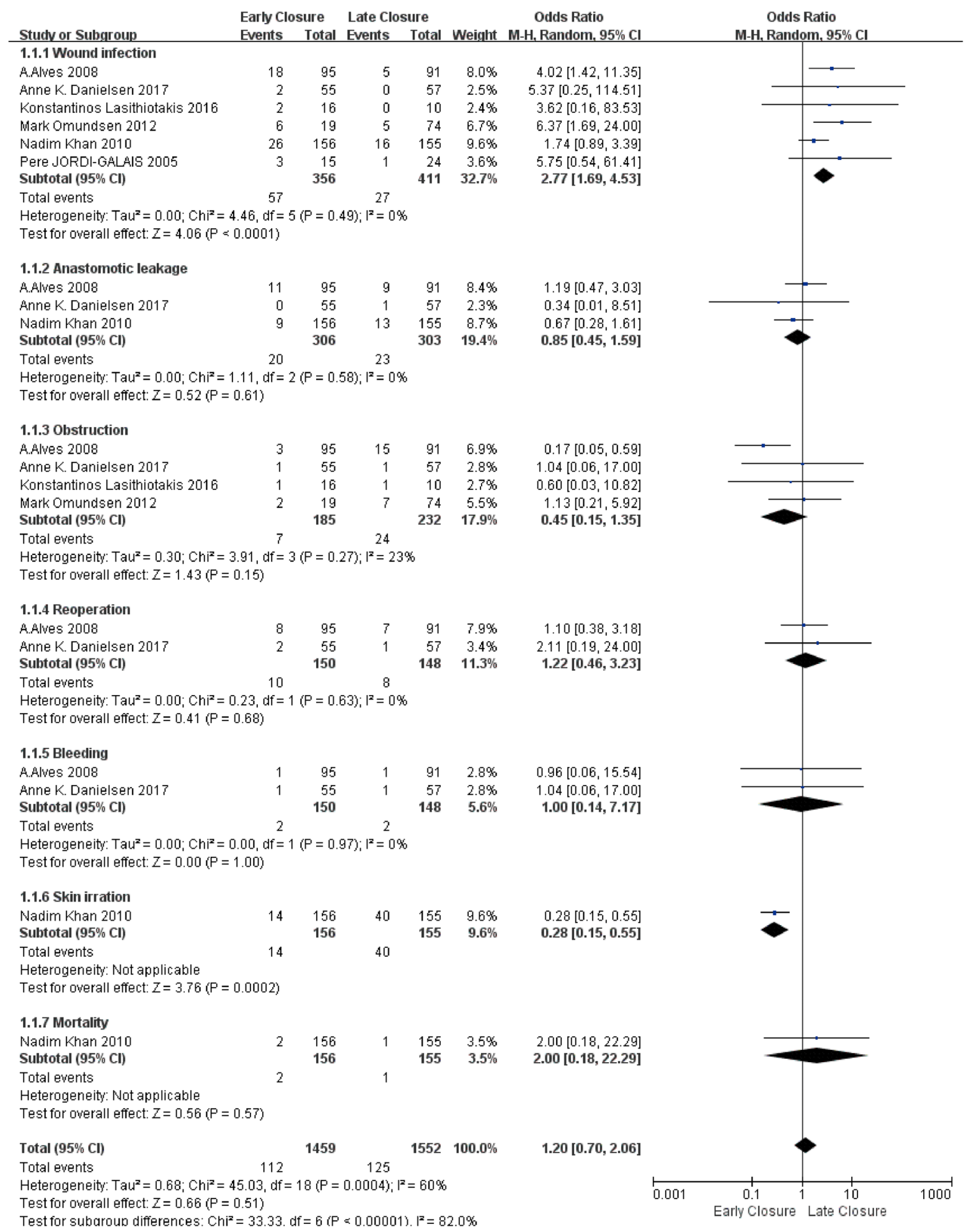

Figure 2: Forest plot for primary outcomes. Forest plot for perioperative complications following early versus late ileostomy closure. Odds ratios are shown with $95 \%$ confidence intervals(CI). No significant difference between the early and late closure groups (OR: $1.20 ; 95 \%$ CI: $0.70-2.06 ; p=0.51)$. 
Compared with previous systematic reviews, the strength of our meta-analysis was that we included the most recent RCT that was reported by Danielsen in 2017 [13]. Our meta-analysis also included three RCTs with 767 participants (356 in the early closure group and 411 in the late closure group). As we assessed a total of three outcomes, the review evidence may be considered conclusive and less biased.

Although stoma-related complications may seem less severe than complications, such as anastomotic leakage and SBO, these complications can be tiresome, distressing, and embarrassing for the patient [38]. However, we found that early closure of a temporary ileostomy had less cases of skin irritation and no worse morbidity outcomes than late closure and that mortality associated with the closing of temporary ileostomy was low, regardless of closure time.

Operative time was significantly not different between the early and late closure groups, which may be attributed to the skin closure method. Further, a meta-analysis in 2015 demonstrated that a pursestring closure had significantly lesser surgical site infections and achieved better cosmetic outcomes following stoma reversal than a conventional primary closure [39]. The hospital stay length after an ileostomy closure was not prolonged; however, in the early closure group, it was suggested that the increased wound infection risk did not significantly delay discharge. In fact, the overall hospital stay length when the admission date for the original operation was considered in the late closure group, tended to be shorter in the early closure group $(p=0.02)$.

Therefore, our meta-analysis suggests that early stoma closure within 4 weeks after proctectomy is feasible and has some advantages in selected patients. This time period is thought to provide minimal delay in closure while still allowing adequate time for anastomotic healing, improving the overall quality-of-life of a patient and reducing healthcare costs [32], despite higher wound infection rates.

However, our meta-analysis has several limitations. First, true double blinding was not achieved in the included trials. Not only were the participants and surgeons aware
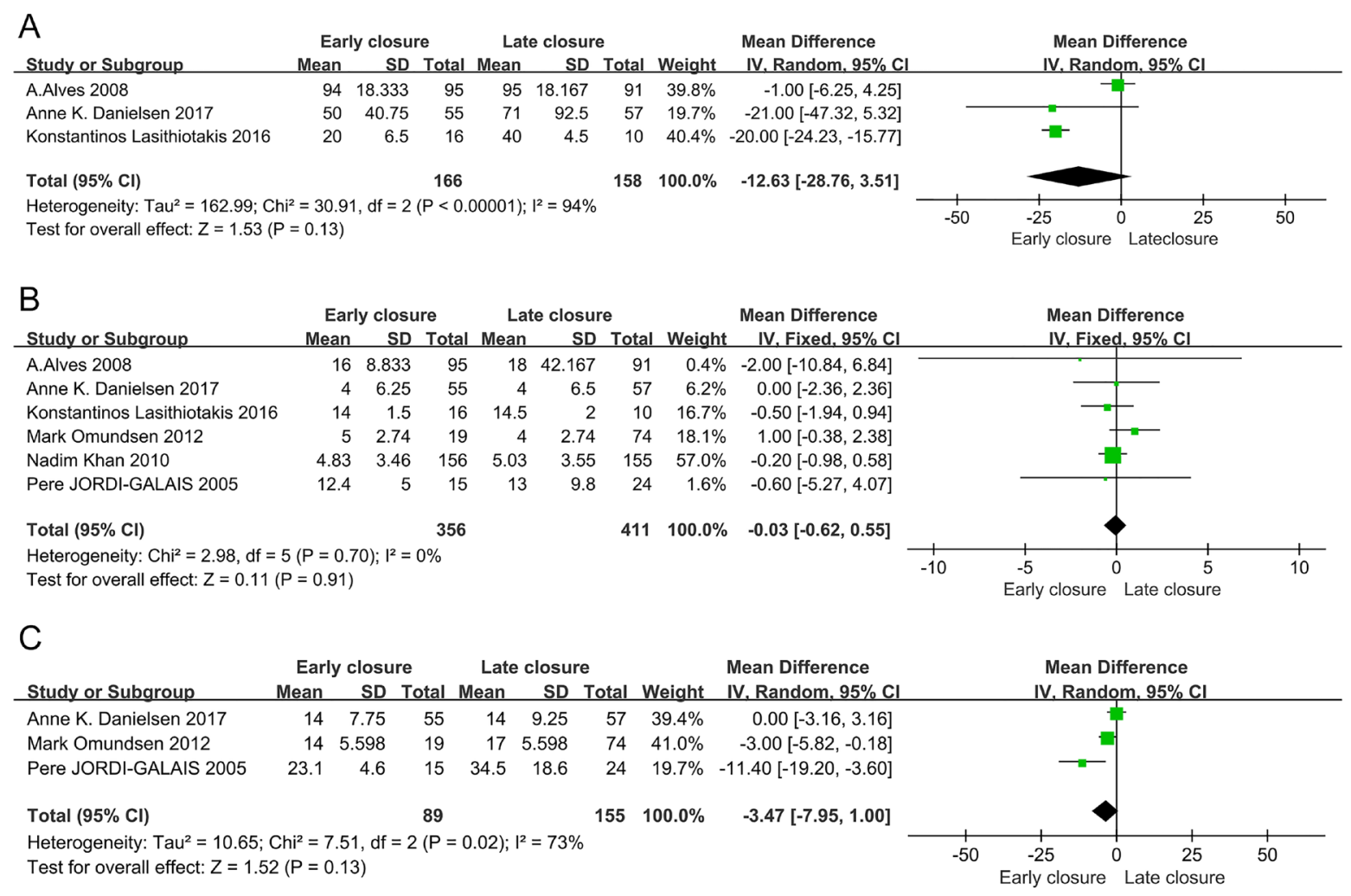

Figure 3: Forest plot for secondary outcomes. (A) Forest plot for the operative time following early versus late ileostomy closure. Standardized mean differences are shown with 95\% CI. No significant difference between the early and late closure groups (WMD 12.63 min shorter in the early closure group, 95\%CI: $-28.76-3.51 ; p=0.13$ ). (B) Forest plot for postoperative hospital duration following early versus late ileostomy closure. Standardized mean differences are shown with 95\% CI. No significant difference between the early and late closure groups (WMD 0.03 days shorter in the early closure group; 95\%CI: $-0.62-0.55 ; p=0.91$ ). (C) Forest plot for total hospital stay length, which was calculated from the date of the initial stoma operation following an early versus late ileostomy closure. Standardized mean differences are shown with $95 \%$ CI. No significant difference between the early and late closure groups (WMD 3.47 days shorter in the early closure group; $95 \% \mathrm{CI}:-7.95-1.00 ; p=0.02$ ). 
of the operative method and allocated group because closure time substantially differed between these groups but also the researcher who conducted the actual coding of the complications was aware, which may have led to observer bias. Second, the low number and quality of included studies weakened the results of our meta-analysis. Our study included RCTs and observational studies, and only three relevant RCTs compared early and late closure of a temporary ileostomy after proctectomy, although we have included the latest RCT. This implies that largescale multicenter trials are warranted for providing more reassuring evidence. Third, this meta-analysis did not address cost efficacy. The cost savings associated with early versus late ileostomy reversal was reported in a

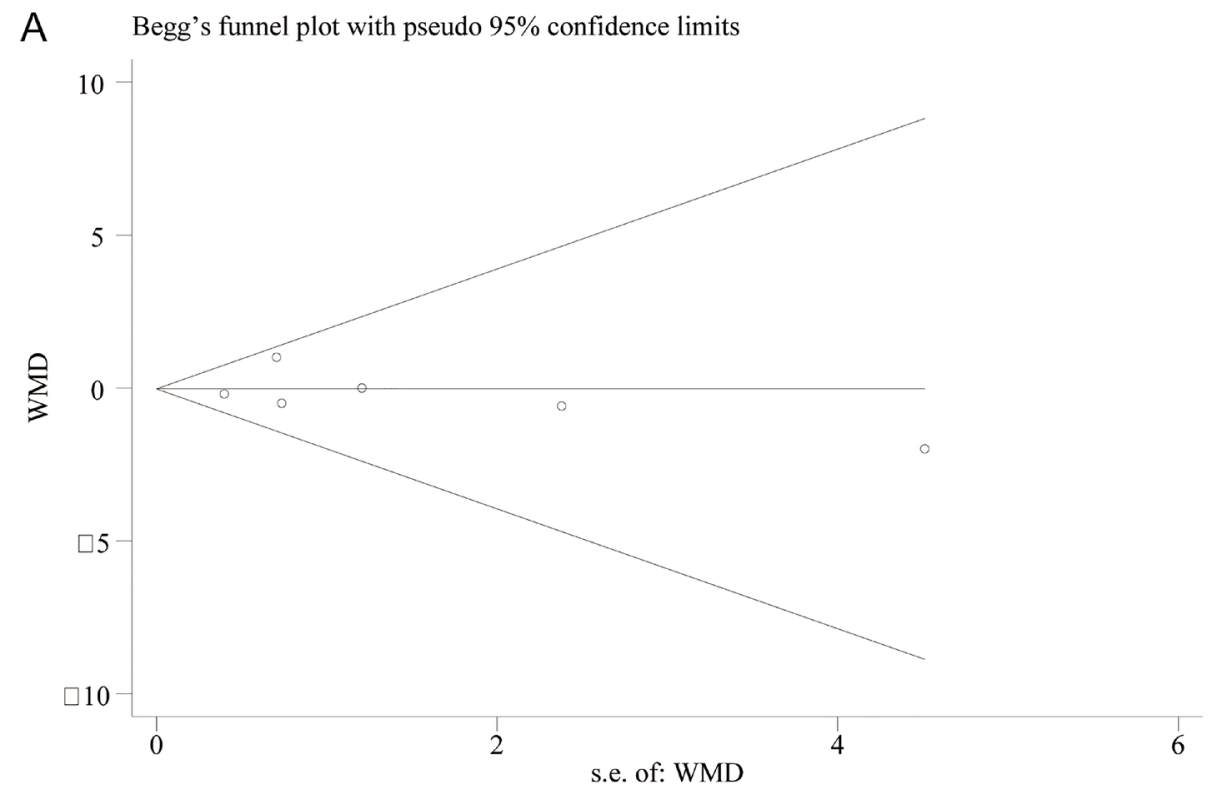

Begg's Test

adj. Kendall's Score $(P-Q)=-1$

Std. Dev. of Score $=5.32$

Number of Studies $=6$

$z=-0.19$

$\operatorname{Pr}>|z|=0.851$

$z=0.00$ (continuity corrected)

$\operatorname{Pr}>|z|=1.000$ (continuity corrected)

B Egger's publication bias plot

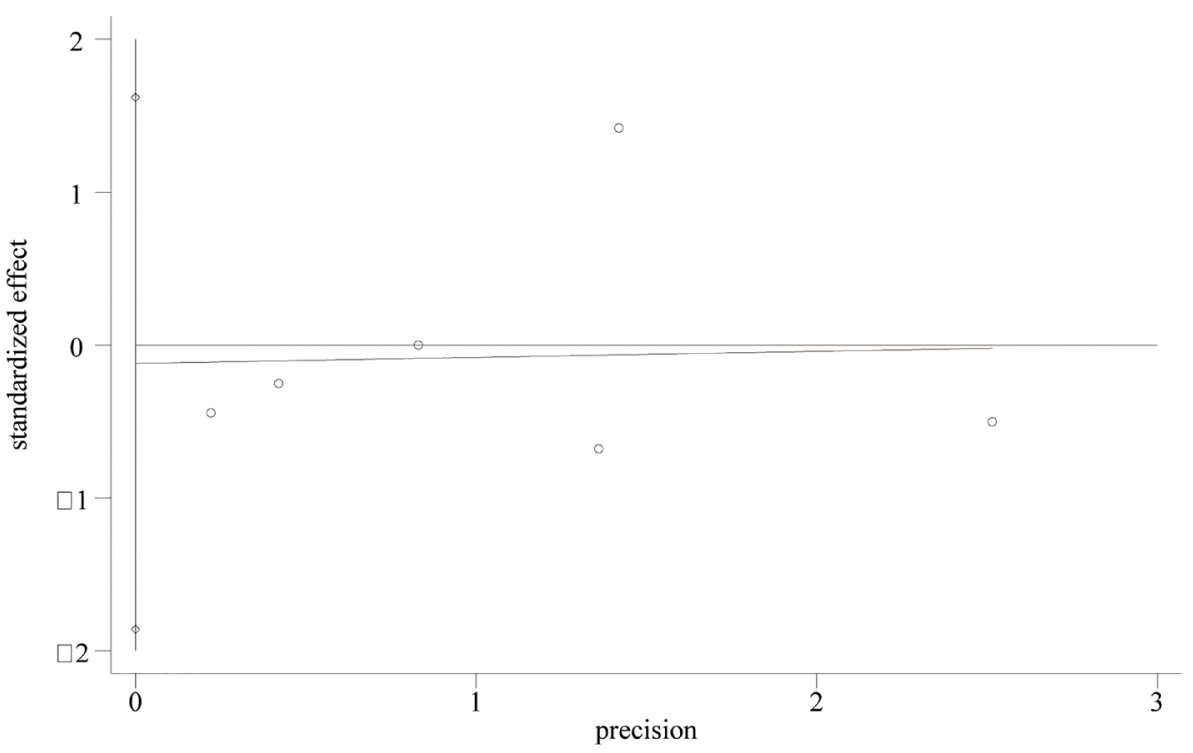

Figure 4: The Begg's test for early closure and late closure did not show any evidence of publication bias. (A) Begg's funnel plot with pseudo 95\% confidence limits. (B) Funnel plot of studies that compared an ileostomy and colostomy for publication bias. 
case-matched study involving 103 patients [40]. Direct hospital costs were compared and it was found that early closure reduced healthcare costs by approximately $25 \%$, despite higher wound infection rates [40]. The overall reduced hospital stay combined with savings in stoma care may make this a cost-effective approach, but further study is needed to clarify this. However, as medical costs vary among countries, each health care system needs to conduct its own cost-effectiveness analysis to support their decision making.

\section{MATERIALS AND METHODS}

\section{Data source and search strategy}

A literature search was performed on July 25, 2017, without restriction to region, publication type, or language. The primary sources were the electronic databases of PubMed, Wiley, Web of Science, and the Cochrane Library. Medical subject headings (MeSH) and free-text words in combination were used in the search for RCTs and observational studies. The following MeSH terms and their combinations were searched in the title/abstract: "ileostomy," "stoma," and "closure." All abstracts, studies, and citations were reviewed. The related articles function was also used to broaden the search, and the computer search was supplemented with manual searches of the reference lists of all retrieved studies, review articles, and conference abstracts. When multiple reports described the same population, the most recent or complete report was used. Authors and device companies were contacted for additional published and unpublished studies.

\section{Inclusion and exclusion criteria}

There were two inclusion criteria for this study: (i) RCTs and prospective and retrospective comparative studies that compared early $(<4$ weeks $)$ with late $(>4$ weeks) closure ileostomies for patients who had undergone an elective procedure for low rectal resection; (ii) reports adult only. Studies were excluded from the analysis if (i) a colostomy was excluded; (ii) relevant data could not be extracted or calculated from the publication; and (iii) if the study was reported as an editorial, letter to the editor, review article, case report, or animal experimental study.

\section{Data extraction and outcomes of interest}

After the removal of duplicates, search items' title and abstract were screened and sequentially excluded, according to the eligibility criteria (Fengxiang Shi and Chunling Wang). If uncertainty remained after screening the title and abstract, the full text was independently scrutinized by two investigators (Shuisheng Zhang and $\mathrm{Xu}$ Che), and discrepancies were resolved by consensus after a discussion. The primary outcomes were perioperative complications that included anastomotic leakage, wound infection, obstruction, or reoperation. Postoperative complications were classified according to the ClavienDindo grading system [41]. Secondary outcomes were operative time, hospital stay length after closure, and total hospital stay length, which was calculated from the date of the initial stoma operation to discharge.

\section{Quality assessment and statistical analysis}

Studies were rated for the level of evidence provided according to the Centre for Evidence-Based Medicine, Oxford, UK, criteria [42]. Provided data were centrally checked for completeness, plausibility, and integrity before they were combined in a single database. The methodological quality of RCTs was assessed by two independent investigators (Biao Zheng and Xiaozhun Huang) according to the Cochrane risk of bias tool [43]. The methodological quality of retrospective and prospective studies was assessed using the modified Newcastle-Ottawa scale [44, 45], which consists of three factors: patient selection, comparability of the study groups, and outcome assessment. A score of 0-9 (assigned as stars) was allocated to each study except RCTs. The RCTs and observational studies with six or more stars were considered to be of high quality. Discrepancies were resolved by consensus after discussion. All the metaanalyses were performed using Review Manager 5.3 (Cochrane Collaboration, Oxford, UK). The WMD and OR were used to compare continuous and dichotomous variables, respectively. All results were reported with $95 \%$ confidence intervals(CI). For studies that presented continuous data as means and range values, standard deviations were calculated using the technique described by Hozo et al. [46]. Statistical heterogeneity between studies was assessed using the chi-square test with significance set at $p<0.10$, and heterogeneity was quantified using the $I^{2}$ statistic. A random effects model was used if there was heterogeneity between studies; otherwise, a fixed effects model was used [47]. Sensitivity analyses were performed for high-quality studies. Publication bias was tested using Stata v. 12.0. Funnel plots were used to screen for potential publication bias.

\section{CONCLUSIONS}

The best available evidence demonstrates that early closure of atemporary ileostomy after proctectomy at 4 weeks shows no significantly increased morbidity, except an increased wound infection rate. No significant differences in the operative time, postoperative hospital stay length, and total hospital stay length for stoma reversal was observed between the early and late closure groups. In conclusion, our meta-analysis suggests that an early stoma closure after proctectomy is feasible in selected patients, and the advantages and disadvantages need to be weighed 
up by the patient and surgeon. More trials with a long-term follow-up are needed to confirm the potential benefit of an early closure stoma for improving overall quality-of-life and its subsequent cost-effectiveness.

\section{Author contributions}

All authors contributed to the study concept, design, data interpretation, and discussion. S-FX, W-CL, $\mathrm{Z}-\mathrm{SS}$, and $\mathrm{C}-\mathrm{X}$ contributed to the screening and data collection. $\mathrm{H}-\mathrm{XZ}$ and $\mathrm{Z}-\mathrm{B}$ contributed to the assessment of the included article. H-XZ, H-ZK, Z-HH, L-H, K-XN, and D-LD contributed to the data analysis. H-XZ, W-CL, $\mathrm{H}-\mathrm{ZK}$, and $\mathrm{Z}-\mathrm{HH}$ contributed to the writing of the manuscript. Z-SS and C-X contributed to provide expert insight into the revision of the manuscript and being as correspondents. All authors approved the final version of the reports.

\section{ACKNOWLEDGMENTS}

The authors acknowledge Tianbao Wang, Ph.D work in National Cancer Center/Cancer Hospital \& Shenzhen Hospital, Chinese Academy of Medical Sciences and Peking Union Medical College, Shenzhen, for the writing assistance and critical revision of the manuscript for important intellectual content.

\section{CONFLICTS OF INTEREST}

The authors disclose no conflicts of interest.

\section{REFERENCES}

1. Matthiessen P, Hallbook O, Rutegard J, Simert G, Sjodahl R. Defunctioning stoma reduces symptomatic anastomotic leakage after low anterior resection of the rectum for cancer: a randomized multicenter trial. Ann Surg. 2007; 246:20714. https://doi.org/10.1097/SLA.0b013e3180603024.

2. Suding P, Jensen E, Abramson MA, Itani K, Wilson SE. Definitive risk factors for anastomotic leaks in elective open colorectal resection. Arch Surg. 2008; 143:907-11; discussion 11-2. https://doi.org/10.1001/archsurg.143.9.907.

3. Montedori A, Cirocchi R, Farinella E, Sciannameo F, Abraha I. Covering ileo- or colostomy in anterior resection for rectal carcinoma. Cochrane Database Syst Rev. 2010:Cd006878. https://doi.org/10.1002/14651858. CD006878.pub2.

4. Tan WS, Tang CL, Shi L, Eu KW. Meta-analysis of defunctioning stomas in low anterior resection for rectal cancer. Br J Surg. 2009; 96:462-72. https://doi.org/10.1002/ bjs. 6594 .

5. Guenaga KF, Lustosa SA, Saad SS, Saconato H, Matos D. Ileostomy or colostomy for temporary decompression of colorectal anastomosis. Cochrane Database Syst Rev.
2007:Cd004647. https://doi.org/10.1002/14651858. CD004647.pub2.

6. Law WL, Chu KW, Choi HK. Randomized clinical trial comparing loop ileostomy and loop transverse colostomy for faecal diversion following total mesorectal excision. Br J Surg. 2002; 89:704-8. https://doi. org/10.1046/j.1365-2168.2002.02082.x.

7. O'Leary DP, Fide CJ, Foy C, Lucarotti ME. Quality of life after low anterior resection with total mesorectal excision and temporary loop ileostomy for rectal carcinoma. Br J Surg. 2001; 88:1216-20. https://doi. org/10.1046/j.0007-1323.2001.01862.x.

8. Huser N, Michalski CW, Erkan M, Schuster T, Rosenberg R, Kleeff J, Friess H. Systematic review and metaanalysis of the role of defunctioning stoma in low rectal cancer surgery. Ann Surg. 2008; 248:52-60. https://doi. org/10.1097/SLA.0b013e318176bf65.

9. den Dulk M, Smit M, Peeters KC, Kranenbarg EM, Rutten HJ, Wiggers T, Putter H, van de Velde CJ. A multivariate analysis of limiting factors for stoma reversal in patients with rectal cancer entered into the total mesorectal excision (TME) trial: a retrospective study. Lancet Oncol. 2007; 8:297-303. https://doi.org/10.1016/s1470-2045(07)70047-5.

10. Thalheimer A, Bueter M, Kortuem M, Thiede A, Meyer D. Morbidity of temporary loop ileostomy in patients with colorectal cancer. Dis Colon Rectum. 2006; 49:1011-7. https://doi.org/10.1007/s10350-006-0541-2.

11. Chow A, Tilney HS, Paraskeva P, Jeyarajah S, Zacharakis E, Purkayastha S. The morbidity surrounding reversal of defunctioning ileostomies: a systematic review of 48 studies including 6,107 cases. Int J Colorectal Dis. 2009; 24:71123. https://doi.org/10.1007/s00384-009-0660-z.

12. Gessler B, Haglind E, Angenete E. Loop ileostomies in colorectal cancer patients--morbidity and risk factors for nonreversal. J Surg Res. 2012; 178:708-14. https://doi. org/10.1016/j.jss.2012.08.018.

13. Danielsen AK, Park J, Jansen JE, Bock D, Skullman S, Wedin A, Marinez AC, Haglind E, Angenete E, Rosenberg J. Early closure of a temporary ileostomy in patients with rectal cancer: a multicenter randomized controlled trial. Ann Surg. 2017; 265:284-90. https://doi.org/10.1097/sla. OT_041847_proofOT_041847_proof1829.

14. Alves A, Panis Y, Lelong B, Dousset B, Benoist S, Vicaut E. Randomized clinical trial of early versus delayed temporary stoma closure after proctectomy. Br J Surg. 2008; 95:693-8. https://doi.org/10.1002/bjs.6212.

15. Elsner A, Walensi M, Zuse A, Munzar T, Dittrich AS, Egger B, Glaser C, Maurer CA. Closure of protective ileostomy 2 v s. 12 weeks following total mesorectal excision for rectal cancer: I nterim analysis of a multicentre, prospective, randomized, c ontrolled study. Brit J Surg. 2015.

16. Lasithiotakis K, Aghahoseini A, Alexander D. Is early reversal of defunctioning ileostomy a shorter, easier and 
less expensive operation? World J Surg. 2016; 40:1737-40. https://doi.org/10.1007/s00268-016-3448-7.

17. Hindenburg T, Rosenberg J. Closing a temporary ileostomy within two weeks. Dan Med Bull. 2010; 57:A4157.

18. Bada-Yllan O, Garcia-Osogobio S, Zarate X, Velasco L, Hoyos-Tello CM, Takahashi T. [Morbi-mortality related to ileostomy and colostomy closure].[Article in Spanish]. Rev Invest Clin. 2006; 58:555-60.

19. Sung N, Kim S, Lee D, Kwak H, Kang D, Ji W, Kwak J, Kim J. Timing of closure for a temporary diverting ileostomy: early closure versus late closure. Dis Colon Rectum. 2014;

20. Park J, Danielsen A, Jansen J, Bock D, Skullman S, Wedin A, Marinez A, Haglind E, Angenete E, Rosenberg J. (2016). Quality of life in the randomised trial EASY - Early closure of a temporary ileostomy after rectal resection for cancer. Colorectal disease Conference: 11th scientific and annual meeting of the european society of coloproctology Italy, pp. 10.

21. Menegaux F, Jordi-Galais P, Turrin N, Chigot JP. Closure of small bowel stomas on postoperative day 10. Eur J Surg. 2002; 168:713-5.

22. Worni M, Witschi A, Gloor B, Candinas D, Laffer UT, Kuehni CE. Early closure of ileostomy is associated with less postoperative nausea and vomiting. Dig Surg. 2011; 28:417-23. https://doi.org/10.1159/000334072.

23. Chand M, Nash GF, Talbot RW. Timely closure of loop ileostomy following anterior resection for rectal cancer. Eur J Cancer Care (Engl). 2008; 17:611-5. https://doi. org/10.1111/j.1365-2354.2008.00972.x.

24. Zhou MW, Wang ZH, Chen ZY, Xiang JB, Gu XD. Advantages of early preventive ileostomy closure after total mesorectal excision surgery for rectal cancer: an institutional retrospective study of 123 consecutive patients. Dig Surg. 2017; 34:305-11. https://doi. org/10.1159/000452676.

25. Zhen L, Wang Y, Zhang Z, Wu T, Liu R, Li T, Zhao L, Deng H, Qi X, Li G. Effectiveness between early and late temporary ileostomy closure in patients with rectal cancer: a prospective study. Curr Probl Cancer. 2017; 41:231-40. https://doi.org/10.1016/j.currproblcancer.2017.02.007.

26. Tulchinsky H, Shacham-Shmueli E, Klausner JM, Inbar M, Geva R. Should a loop ileostomy closure in rectal cancer patients be done during or after adjuvant chemotherapy? J Surg Oncol. 2014; 109:266-9. https://doi.org/10.1002/ jso.23493.

27. Boman-Sandelin K, Fenyo G. Construction and closure of the transverse loop colostomy. Dis Colon Rectum. 1985; 28:772-4.

28. Bakx R, Busch OR, van Geldere D, Bemelman WA, Slors JF, van Lanschot JJ. Feasibility of early closure of loop ileostomies: a pilot study. Dis Colon Rectum. 2003; 46:1680-4. https://doi.org/10.1097/01. dcr.0000093823.42029.f2.
29. Deltell Colomer P, Albertos Mira-Marceli N, Gallego Mellado N, Kuan Arguello ME, Bordallo Vazquez MF, Mira Navarro J, Gonzalvez Pinera J. [Ileostomy closure after necrotizing enterocolitis. When is the best moment?]. [Article in Spanish]. Cir Pediatr. 2015; 28:55-8.

30. Struijs MC, Poley MJ, Meeussen C, Madern GC, Tibboel D, Keijzer R. Late vs early ostomy closure for necrotizing enterocolitis: analysis of adhesion formation, resource consumption, and costs. J Pediatr Surg. 2012; 47:658-64. https://doi.org/10.1016/j.jpedsurg.2011.10.076.

31. Al-Hudhaif J, Phillips S, Gholum S, Puligandla PP, Flageole $\mathrm{H}$. The timing of enterostomy reversal after necrotizing enterocolitis. J Pediatr Surg. 2009; 44:924-7. https://doi. org/10.1016/j.jpedsurg.2009.01.028.

32. Khan N, Bangash A, Hadi A, Ahmad M, Sadiq M. Is early closure of stoma warranted in the management of temporary loop ileostomy? J Postgrad Med Inst. 2010; 24:295-300.

33. Omundsen $\mathrm{M}$, Hayes $\mathrm{J}$, Collinson $\mathrm{R}$, Merrie A, Parry B, Bissett I. Early ileostomy closure: is there a downside? ANZ J Surg. 2012; 82:352-4. https://doi. org/10.1111/j.1445-2197.2012.06033.x.

34. Jordi-Galais P, Turrin N, Tresallet C, Nguyen-Thanh Q, Chigot J, Menegaux F. (2003). Early closure of temporary stoma of the small bowel. Gastroenterol Clin Biol. 2003; 27:697-9.

35. Senapati A, Nicholls RJ, Ritchie JK, Tibbs CJ, Hawley PR. Temporary loop ileostomy for restorative proctocolectomy. Br J Surg. 1993; 80:628-30.

36. Perez RO, Habr-Gama A, Seid VE, Proscurshim I, Sousa AH Jr, Kiss DR, Linhares M, Sapucahy M, GamaRodrigues J. Loop ileostomy morbidity: timing of closure matters. Dis Colon Rectum. 2006; 49:1539-45. https://doi. org/10.1007/s10350-006-0645-8.

37. Robertson JP, Puckett J, Vather R, Jaung R, Bissett I. Early closure of temporary loop ileostomies: a systematic review. Ostomy Wound Manage. 2015; 61:50-7.

38. Sun V, Grant M, McMullen CK, Altschuler A, Mohler MJ, Hornbrook MC, Herrinton LJ, Baldwin CM, Krouse RS. Surviving colorectal cancer: long-term, persistent ostomyspecific concerns and adaptations. J Wound Ostomy Continence Nurs. 2013; 40:61-72. https://doi.org/10.1097/ WON.0b013e3182750143.

39. Hsieh MC, Kuo LT, Chi CC, Huang WS, Chin CC. Pursestring closure versus conventional primary closure following stoma reversal to reduce surgical site infection rate: a meta-analysis of randomized controlled trials. Dis Colon Rectum. 2015; 58:808-15. https://doi.org/10.1097/ dcr.OT_041847_proofOT_041847_proof0401.

40. Robertson J, Linkhorn H, Vather R, Jaung R, Bissett IP. Cost analysis of early versus delayed loop ileostomy closure: a case-matched study. Dig Surg. 2015; 32:166-72. https://doi.org/10.1159/000375324.

41. Clavien PA, Barkun J, de Oliveira ML, Vauthey JN, Dindo D, Schulick RD, de Santibanes E, Pekolj J, Slankamenac 
K, Bassi C, Graf R, Vonlanthen R, Padbury R, et al. The Clavien-Dindo classification of surgical complications: five-year experience. Ann Surg. 2009; 250:187-96. https:// doi.org/10.1097/SLA.0b013e3181b13ca2.

42. Phillips B, Ball C, Sackett D. Levels of evidence and grades of recommendation. Oxford Centre for Evidencebased Medicine Website. http://www.cebm.net/index. $\operatorname{aspx} ? \mathrm{o}=1025$.

43. Higgins JP, Altman DG, Gotzsche PC, Juni P, Moher D, Oxman AD, Savovic J, Schulz KF, Weeks L, Sterne JA. The Cochrane Collaboration's tool for assessing risk of bias in randomised trials. BMJ. 2011; 343:d5928. https:// doi.org/10.1136/bmj.d5928.

44. Taggart DP, D'Amico R, Altman DG. Effect of arterial revascularisation on survival: a systematic review of studies comparing bilateral and single internal mammary arteries. Lancet. 2001; 358:870-5. https://doi.org/10.1016/ s0140-6736(01)06069-x.
45. Wells G, Shea B, O'Connell D. The Newcastle-Ottawa Scale (NOS) for assessing the quality of nonrandomised studies in meta-analyses. Ottawa Hospital Research Institute Website. http://www.ohri.ca/programs/clinical_ epidemiology/oxford.asp.

46. Hozo SP, Djulbegovic B, Hozo I. Estimating the mean and variance from the median, range, and the size of a sample. BMC Med Res Methodol. 2005; 5:13. https://doi. org/10.1186/1471-2288-5-13.

47. Higgins J, Green S. Cochrane handbook for systematic reviews of interventions. New York, NY: Cochrane Collaboration, John Wiley and Sons; 2008. 